\title{
Karakteristik Kawasan Wisata Pantai Paseban Berdasarkan Konsep Pariwisata Berkelanjutan di Kabupaten Jember
}

\author{
Sari Diwanti Putri dan Hertiari Idajati \\ Departemen Perencanaan Wilayah dan Kota, Fakultas Arsitektur, Desain dan Perencanaan, \\ Institut Teknologi Sepuluh Nopember (ITS) \\ e-mail: ide_archits@yahoo.com
}

\begin{abstract}
Abstrak-Pantai Paseban merupakan salah satu pantai di Kabupaten Jember yang memiliki daya tarik baik dari segi wisata alam maupun budaya. Namun, potensi tersebut belum dikembangkan dengan optimal. Dimana terdapat kerusakan ekosistem mangrove dan adanya ancaman penambangan pasir besi yang akan dilakukan oleh pihak swasta sedangkan nilai ekonomi pasir besi yang tinggi menyebabkan masyarakat tergiur untuk melakukan penambangan serta pendapatan nelayan sekitar yang masih tergolong kecil. Upaya yang dapat dilakukan untuk meminimalisir dampak negatif yang terjadi yaitu melalui arahan pengembangan wisata dimana responden penelitian dilakukan kepada empat responden yang terdiri dari kelompok pemerintah, swasta, dan masyarakat. Guna mencapai hal tersebut diperlukan identifikasi karakteristik melalui content analysis. Hasil dari penelitian ini menunjukkan bahwa karakteristik kawasan wisata Pantai Paseban belum memenuhi prinsip pariwisata keberlanjutan khususnya dari segi lingkungan dimana lingkungan pantai belum dimanfaatkan secara optimal untuk kegiatan wisata, masih adanya ancaman penambangan pasir besi, belum ada upaya untuk mengurangi abrasi dan kendaraan pribadi, pelayanan jaringan listrik yang belum memanfaatkan SDA, pembuangan limbah warung makan dan kamar mandi umum yang langsung ke tanah, penggunaan iar tanah sebagai sumber pelayanan air bersih, serta upaya pemusnahan sampah dengan cara dibakar. Sedangkan aspek sosial dan ekonomi memiliki kondisi yang lebih baik dibandingkan dengan aspek lingkungan.
\end{abstract}

Kata Kunci-Content Analysis, Karakteristik, Pantai Paseban, Pariwisata Berkelanjutan.

\section{PENDAHULUAN}

$\mathrm{P}$ ARIWISATA alam memiliki tingkat pertumbuhan yang paling besar dibandingkan dengan pariwisata lainnya dengan nilai pertumbuhan sebesar $20 \%$ dari total perjalanan internasional [1]. Indonesia merupakan negara kepulauan dengan garis pantai terpanjang kedua di dunia yaitu 99,093 $\mathrm{km}$. Dengan luasnya kawasan pesisir tersebut, Indonesia memanfaatkan potensi tersebut untuk dikembangkan menjadi kegiatan pariwisata pantai. Menurut dokumen [2], Kabupaten Jember merupakan salah satu kabupaten di Jawa Timur yang di arahkan pengembangannya dalam sektor pariwisata. Keberadaan wilayah pesisir menyebabkan Kabupaten Jember memiliki potensi kelautan yang cukup besar. Potensi kelautan ini kemudian dimanfaatkan sebagai salah satu kawasan wisata alam berupa pantai salah satunya yaitu Pantai
Paseban.

Pantai Paseban memiliki keunikan di bandingkan dengan pantai-pantai lainnya di Kabupaten Jember baik keunikan dari daya tarik wisata alam maupun daya tarik wisata budaya. Daya tarik wisata alam yang dimiliki Pantai Paseban yaitu pantai pasir besi halus dan bukit pasir hitam, terdapat kebun semangka, dan tempat yang strategis untuk melihat Pulau Nusa Barong. Sedangkan daya tarik wisata budaya yang ada meliputi petik laut, tanggap wayang, dan pekan raya yang berlangsung setiap tanggal 1-10 Syawal [3].

Sayangnya, potensi yang ada belum dikembangkan secara optimal [2]. Ekosistem mangrove yang merupakan salah satu potensi daya tarik wisata saat ini mengalami kerusakan. Hal tersebut dapat dilihat bahwa pada tahun 2016 sebaran mangrove seluas 2 ha [4], namun kerapatan hutan mangrove saat ini seluas 0 ha. Selain itu, pada tahun 2010 terdapat ancaman penambangan pasir besi yang akan dilakukan oleh PT. Dwi Agita Sejahtera. Pada hal, berdasarkan dokumen [5] menjelaskan bahwa kawasan pariwisata pantai tidak diperuntukkan untuk kegiatan penambangan pasir besi.

Disisi lain, kondisi substrat Pantai Paseban yang merupakan pasir besi memiliki nilai ekonomi yang tinggi [3]. Hal tersebut menyebabkan adanya ketertarikan bagi masyarakat setempat untuk melakukan penambangan. Selain itu, pendapatan nelayan sekitar juga masih tergolong kecil [6].

Melihat beberapa permasalahan di atas, hal ini tidak dapat diabaikan begitu saja karena akan mengancam keberlanjutan dari pariwisata itu sendiri. Seiring dengan berjalannya waktu, konsep pariwisata akan terus berkembang atau mengalami perubahan [7]. Saat ini, pembangunan ditekankan pada prinsip pembangunan berkelanjutan (sustainable development), dengan adanya konsep pembangunan berkelanjutan tersebut kemudian di adopsi kedalam konsep pembangunan pariwisata berkelanjutan (sustainable tourism development) [8]. Pariwisata yang berkelanjutan adalah pariwisata yang dapat menjamin keberlangsungan sumber daya alam dan kehidupan sosial-budaya serta memberikan manfaat ekonomi pada generasi sekarang hingga yang akan datang sehingga dapat menjawab kebutuhan pengunjung, industri (pariwasata), lingkungan, dan masyarakat [9].

Saat ini, Pantai Paseban masih memerlukan arahan untuk merealisasikan elemen-elemen di dalam pariwisata yang berkelanjutan. Untuk itu perlu adanya identifikasi karakteristik pariwisata secara berkelanjutan agar 
pengembangan wisata yang dilakukan sesuai dengan kebutuhan.

\section{METODE PENELITIAN}

\section{A. Jenis dan Pendekatan Penelitian}

Pada penelitian ini, pendekatan yang dilakukan adalah pendekatan penelitian rasionalistik. Jenis penelitian ini adalah penelitian deskriptif kualitatif.

\section{B. Variabel Penelitian}

Indikator yang akan dibahas dalam penelitian ini terdiri dari 3 hal yaitu, lingkungan, sosial budaya, dan ekonomi. Adapun sub-variabel yang digunakan untuk mengukur tiap indikator dapat dilihat pada Tabel 1 .

Tabel 1.

Indikator, Variabel, dan Sub Variabel Penelitian

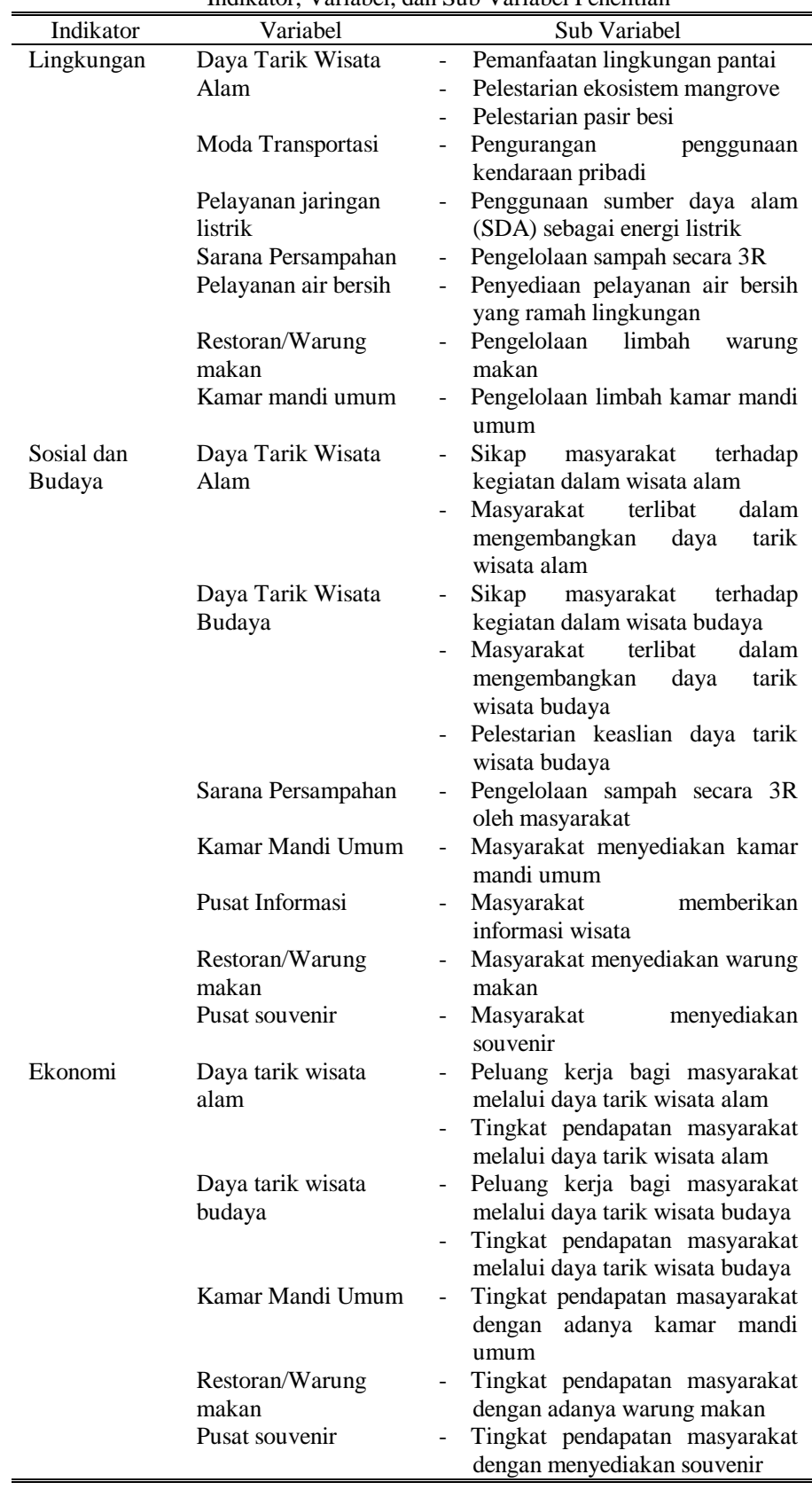

\section{Metode Pengumpulan Data}

Metode pengumpulan data yang digunakan dalam penelitian ini adalah survei primer dan survei sekunder. Survei primer dilakukan melalui observasi, wawancara secara in-depth interview dan participatory mapping terhadap stakeholders terkait yang terdiri dari kelompok pemerintah (Dinas Pariwisata dan Kebudayaan Kabupatten Jember dan Kepala Desa Paseban), kelompok swasta (pelaku usaha warung makan), dan kelompok masyarakat (Kelompok Aliansi Masyarakat Peduli Lingkungan). Berikut merupakan tahapan proses participatory mapping :

1. Tahap Observasi Lapangan

Pada tahap ini hal-hal yang harus dilakukan peneliti yaitu :

a. Melakukan observasi lapangan untuk mengenali lokasilokasi yang merupakan karakteristik di wilayah studi seperti penggunaan lahan dan sarana wisata dimana hasil observasi akan dipetakan ke dalam peta dasar yang telah di print.

b. Mapping hasil observasi ke dalam software ArcGIS

c. Menyiapkan data non spasial : form wawancara dan pemetaan stakeholders

\section{Tahap Wawancara}

Pada tahap ini stakeholders dapat menyampaikan opininya terkait karakteristik di wilayah studi secara eksploratif dan melalukan pemetaan. Eksplorasi karakteristik di wilayah studi didasarkan atas sub variabel yang telah di tentukan. Hasil dari tahap ini berupa peta dan transkrip.

\section{Tahap Validasi Data}

Pada tahap ini, peneliti menggabungkan hasil kegiatan participatory mapping ke dalam software ArcGIS dengan menggunakan teknik overlay, sehingga hasil yang didapatkan berupa informasi terkait karakteristik Pantai Paseban berdasarkan aspek lingkungan, sosial budaya, dan ekonomi

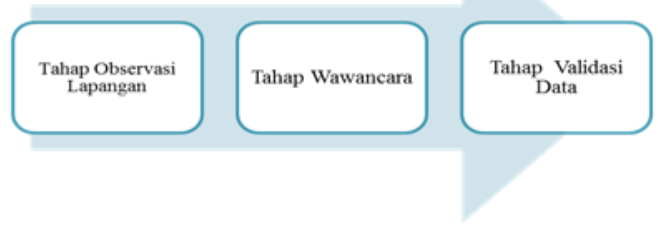

Gambar 1. Diagram Alur Proses Particpatory Mapping.

Sedangkan untuk survei sekunder dilakukan dengan studi literature dan survei instansi untuk memperoleh gambaran umum penelitian.

\section{Metode Analisis}

Untuk mengetahui karaketeristik kawasan wisata Pantai Paseban dan keberlanjutan kawasan wisata Pantai Paseban metode analisis yang digunakan yaitu content analysis. Content analysis adalah teknik analisa yang berfungsi untuk merekam dan menganalisis keberadaan kalimat dan konsep secara spesifik dalam sebuah sampel teks yang sifatnya replicable dan valid.

Berikut merupakan kode stakeholders dan sub variabel penelitian yang akan digunakan untuk melakukan proses pengkodean pada transkrip wawancara. 
Tabel 2 .

Kode Stakeholders Dalam Penelitian

\begin{tabular}{ccl}
\hline \hline Huruf & Angka & \multicolumn{1}{c}{ Stakeholderss } \\
\hline $\mathrm{G}$ & 1 & $\begin{array}{l}\text { Dinas Kebudayaan dan Pariwisata Kabupaten } \\
\text { Jember }\end{array}$ \\
$\mathrm{G}$ & 2 & $\begin{array}{l}\text { Kelurahan Desa Paseban } \\
\text { Pedagang Kaki Lima } \\
\mathrm{S}\end{array}$ \\
$\mathrm{K}$ & & $\begin{array}{l}\text { Kelompok Aliansi Masyarakat Peduli } \\
\text { Lingkungan Desa Paseban (AMPEL) }\end{array}$ \\
\hline \hline
\end{tabular}

Maka Dinas Kebudayaan dan Pariwisata Kabupaten Jember dikodekan G1

G2 : Nah iya sudah kami lakukan, satu kali dua kali tiga kali gagal tanan karena memang bukan ahlinya. Udah kerja sama UNEJ juga waktu nanam mangrove itu sama Prof Darmaji itu, dia ahli menanam mangrove dan cemara itu, kamipun juga sudah studi banding ke Tuban ke panangkar cemara disana. Sudah banyak hal kami lakukan sesungguhnya tetapi karena harus di barengi termasuk skill dan anggaran. Tanpa anggaran juga kita tanpa logistik logika kita gak jalan.

*) Kode : "V2.5"

V2: Sub variabel kedua yaitu pelestarian ekosistem mangrove

5 : Urutan kutipan paragraf ke-5 dalam transkrip

Gambar 3. kutipan temuan kode dalam transkrip wawancara.

Tabel 3 .

Kode Sub Variabel dalam Penelitian

\begin{tabular}{cl}
\hline \hline Angka & \multicolumn{1}{c}{$\begin{array}{c}\text { Sub variabel faktor pengembangan wisata pantai secara } \\
\text { berkelanjutan (Kode : V) }\end{array}$} \\
\hline 1 & Pemanfaatan lingkungan pantai \\
2 & Pelestarian ekosistem mangrove \\
3 & Pelestarian pasir besi \\
5 & Pengurangan penggunaan kendaraan pribadi \\
6 & Pengunaan sumber daya alam (SDA) sebagai energi listrik \\
7 & Pengelolaan sampah secara 3R pelayanan air bersih yang ramah lingkungan \\
8 & Pengelolaan limbah warung makan \\
9 & Pengelolaan limbah kamar mandi umum \\
10 & Sikap masyarakat terhadap kegiatan dalam wisata alam \\
11 & Masyarakat terlibat dalam mengembangkan daya tarik wisata \\
12 & alam \\
13 & Maskap masyarakat terhadap kegiatan dalam wisata budaya \\
14 & budaya terlibat dalam mengembangkan daya tarik wisata \\
15 & Pelestarian keaslian daya tarik wisata budaya \\
16 & Mengelolaan sampah secara 3R oleh masyarakat \\
17 & Masyarakat menyediakan kamar mandi umum \\
18 & Masyarakat menyediakan warung makan \\
19 & Masyarakat menyediakan souvenir \\
20 & Lapangan kerja bagi melalui daya tarik wisata alam \\
21 & Tingkat pendapatan melalui daya tarik wisata alam \\
22 & Lapangan kerja melalui daya tarik wisata budaya \\
23 & Tingkat pendapatan melalui daya tarik wisata budaya \\
24 & Tingkat pendapatan masayarakat dengan adanya kamar mandi \\
25 & umum \\
26 & Tingkat pendapatan masyarakat dengan adanya warung makan \\
\hline \hline contoh : V1 : menunjukkan penjelasan sub variabel pemanfaatan lingkungan \\
pantai. &
\end{tabular}

\section{HASIL DAN DISKUSI}

Pada bab hasil dan diskusi tahapan yang akan dibahas yaitu pada tahap pengkodean, penyederhanaan data dan pemahaman karena tahap pengunitan dan pembatasan penelitian sudah dijelaskan pada bab metode penelitian.

\section{A. Hasil Pengkodean dan Penyederhanaan Data}

Pengkodean dilakukan untuk menemukan kode yang mengindikasikan karakteristik setiap sub variabel penelitian. Hasil pengkodean didasarkan pada transkrip wawancara 4 stakeholders yang sebelumnya telah dilakukan secara mendalam. Penemuan kode dalam transkrip wawancara dapat dilihat pada Gambar 3.

Berdasarkan Gambar 3, diketahui bahwa terdapat unit analisis yang disampaikan oleh stakeholder 2 (G2) yang mengindikasikan makna sub variabel pelestarian ekosistem mangrove (V2). Stakeholder 2 menjelaskan bahwa upaya penanaman kembali mangrove yang mati dilakukan melalui pembekalan edukasi dari UNEJ dan studi banding ke penangkaran cemara laut di Tuban.

\section{B. Hasil Pemahaman Data}

Berdasarkan hasil pengkodean,berikut adalah karakteristik kawasan wisata Pantai Paseban secara berkelanjutan :

1) Aspek Lingkungan

Tabel 4. Content Analysis pada Aspek Lingkungan

\begin{tabular}{|c|c|c|}
\hline \multirow{2}{*}{ Sub Variabel } & \multicolumn{2}{|c|}{ Indikasi } \\
\hline & Terpenuhi & Tidak Terpenuhi \\
\hline $\begin{array}{l}\text { Pemanfaatan lingkungan } \\
\text { pantai }\end{array}$ & $\begin{array}{c}\text { G1.1, G1.2, G2.1, } \\
\text { G2.2, G2.3, G2.4, } \\
\text { M.1, M.2, M.3, M.4, } \\
\text { M.6, S.1, S.2, S.3, } \\
\text { S.4 }\end{array}$ & M.5 \\
\hline $\begin{array}{l}\text { Pelestarian ekosistem } \\
\text { mangrove }\end{array}$ & $\begin{array}{c}\mathrm{G} 2.1, \mathrm{G} 2.2, \\
\mathrm{M} .1, \mathrm{M} .2, \mathrm{M} .3, \mathrm{~S} .1\end{array}$ & $\begin{array}{l}\text { G2.3, G2.4, G2.5, M.4, } \\
\text { M.5, S.2 }\end{array}$ \\
\hline Pelestarian pasir besi & & $\begin{array}{c}\text { G2.1, G2.2, G2.3, } \\
\text { G2.4, M.1, M.2, M.3, } \\
\text { M.4 }\end{array}$ \\
\hline $\begin{array}{l}\text { Pengurangan penggunaan } \\
\text { kendaraan pribadi }\end{array}$ & & $\begin{array}{c}\text { G1.1, G1.2, G2.2, } \\
\text { G2.2, M.1, S.1 }\end{array}$ \\
\hline $\begin{array}{l}\text { Penggunaan sumber daya } \\
\text { alam (SDA) sebagai energi } \\
\text { listrik }\end{array}$ & & $\begin{array}{c}\text { G2.1, G2.2, M.1, M.2, } \\
\text { S.1, S.2 }\end{array}$ \\
\hline $\begin{array}{l}\text { Pengelolaan sampah secara } \\
3 \mathrm{R}\end{array}$ & & $\begin{array}{c}\text { G1.1, G1.2, G2.1, } \\
\text { G2.2, G2.3, M.1, M.2, } \\
\text { S.1, S.2, S.3 }\end{array}$ \\
\hline $\begin{array}{l}\text { Penyediaan pelayanan air } \\
\text { bersih yang ramah }\end{array}$ & & $\begin{array}{c}\text { G1.1, G2.1, G2.2, } \\
\text { G2.3, G2.4, M.1, M.2, }\end{array}$ \\
\hline lingkungan & & M.3, S.1, S.2, S.3 \\
\hline $\begin{array}{l}\text { Pengelolaan limbah } \\
\text { warung makan }\end{array}$ & & $\begin{array}{c}\text { G1.1, G2.1, G2.2, M.1, } \\
\text { M.2, M.3, S.1 }\end{array}$ \\
\hline $\begin{array}{l}\text { Pengelolaan limbah kamar } \\
\text { mandi umum }\end{array}$ & & $\begin{array}{c}\text { G1.1, G2.1, G2.2, M.1, } \\
\text { M.2, M.3, S.1, } \\
\end{array}$ \\
\hline $\begin{array}{l}\text { *) Kode : "Ax.y" } \\
\text { Ax }=\text { Kode stakeholder }\end{array}$ & & \\
\hline
\end{tabular}

Berdasarkan tabel di atas, dapat disimpulkan bahwa dalam aspek lingkungan memiliki karakteristik positif dan negatif dimana karakteristik positif atau yang terpenuhi yaitu sudah ada upaya penanaman kembali ekosistem mangrove melalui kerja sama dengan berbagai pihak untuk menanam cemara laut dan melakukan studi banding ke penangkaran cemara laut namun penanaman tidak dapat dilakukan dalam jumlah banyak karena belum ada pengontrolan jumlah pengunjung.

Sayangnya, masih terdapat beberapa kondisi yang belum terpenuhi, yaitu :

1. Lingkungan pantai bekum dimanfaatkan secara optimal untuk kegiatan wisata, hal tersebut dapat dilihat dari adanya 
lahan kebun semangka yang belum dimanfaatkan sebagai agrowisata.

2. Belum ada upaya pelestarian pasir besi akibat abrasi dan masih ada ancaman dari investor untuk melakukan kegiatan penambangan pasir besi

3. Belum ada pengurangan penggunaan kendaraan pribadi seperti penyediaan angkutan umum karena saat ini angkutan umum baru melayani kawasan wisata yang ramai dikunjungi wisatawan seperti Pantai Papuma, Payangan, dan Watu
Ulo.Belum memanfaatkan SDA seperti cahaya matahari, angin, dan gelombang sebagai sumber pelayanan listrik 4. Kegiatan pengelolaan sampah hanya sebatas kerja bakti yang dilaksanakan setiap hari Jumat namun kegiatan tersebut belum menerapkan prinsip 3R. Saat ini masyarakat memusnahkan sampah dengan cara di bakar

5. Pelayanan air bersih yang masih menggunakan air tanah 6. Pembungan limbah warung makan dan kamar mandi umum langsung ke pasir melalui saluran terbuka.

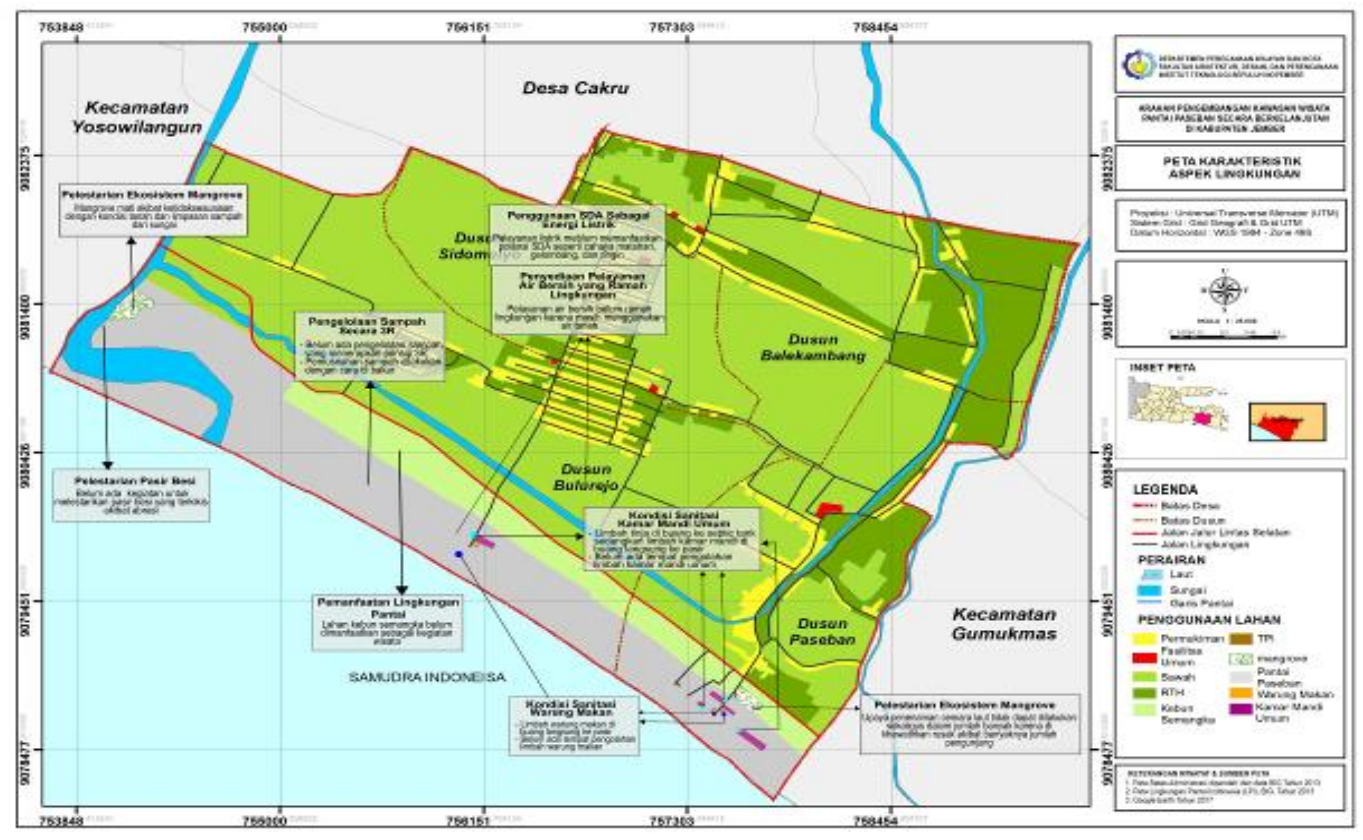

Gambar 4. Peta Karakteristik Aspek Lingkungan

Sumber : Penulis, 2018

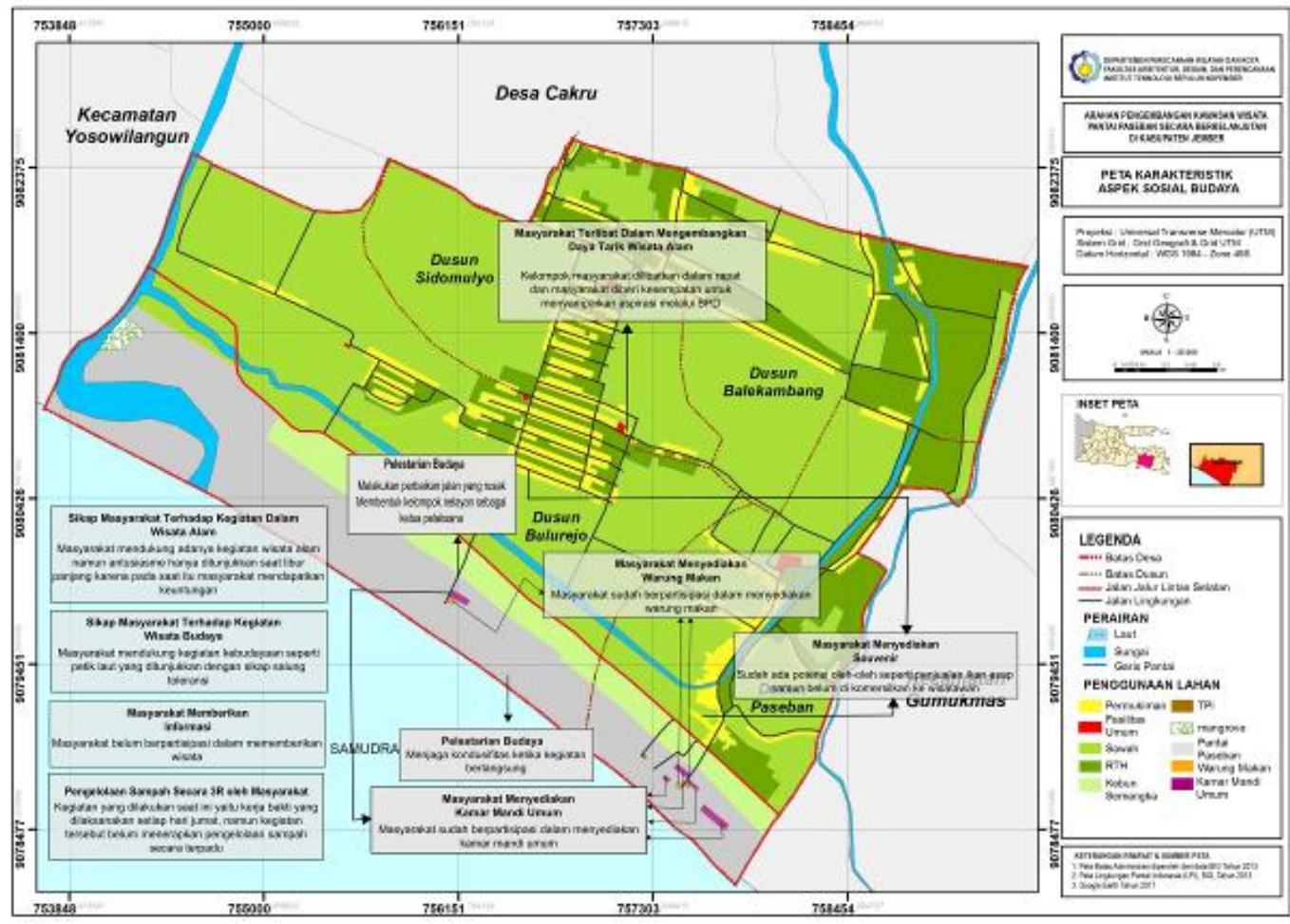

Gambar 4. Peta Karakteristik Aspek Sosial dan Budaya.

Sumber : Penulis, 2018 


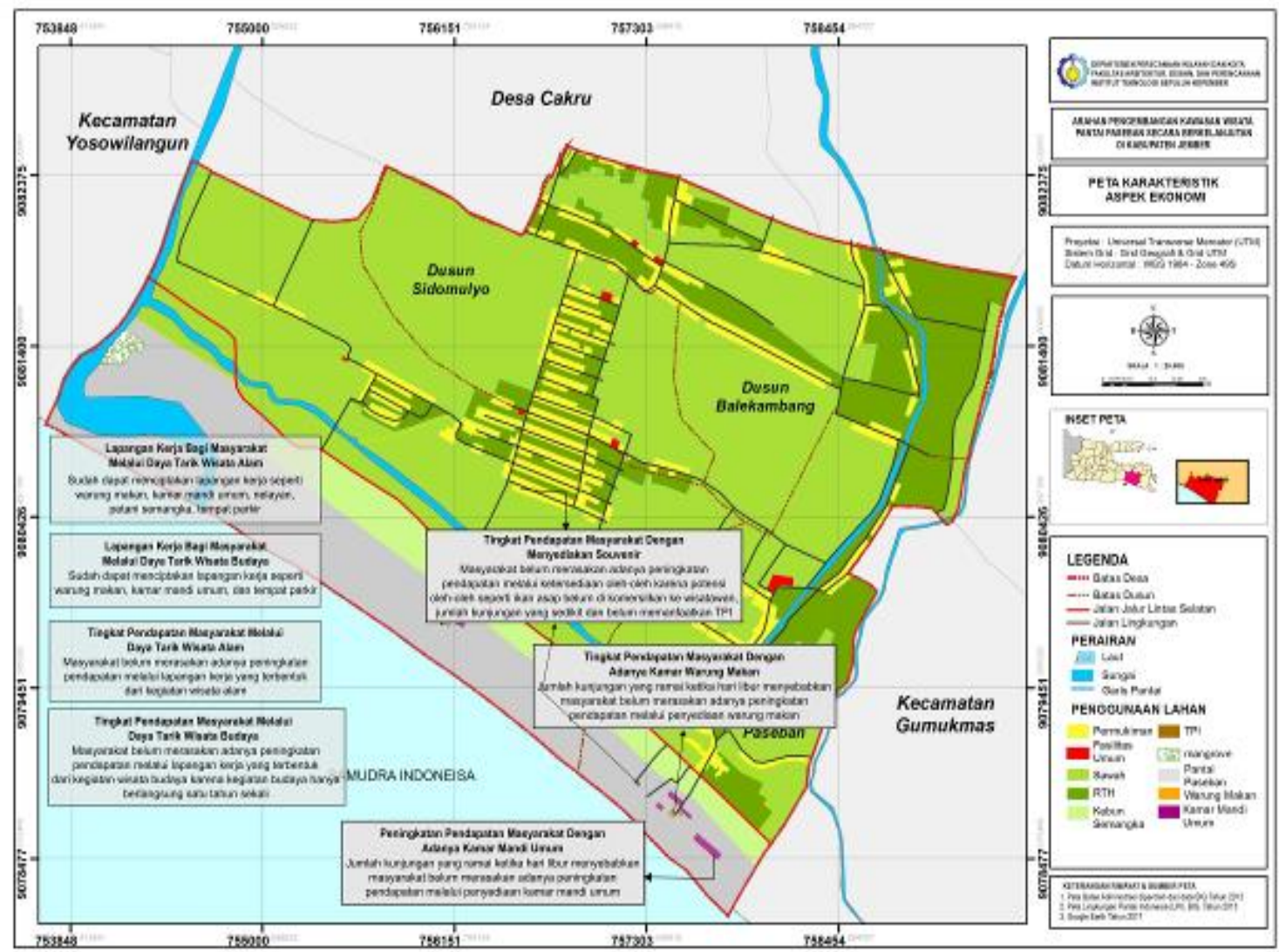

Gambar 4. Peta Karakteristik Aspek Ekonomi

Sumber : Penulis, 2018

\section{Aspek Sosial dan Budaya}

Tabel 5.

Content Analysis pada Aspek Sosial dan Budaya

\begin{tabular}{|c|c|c|}
\hline \multirow{2}{*}{ Sub Variabel } & \multicolumn{2}{|c|}{ "Indikasi } \\
\hline & Terpenuhi & Terpenuhi \\
\hline $\begin{array}{l}\text { Sikap masyarakat terhadap } \\
\text { kegiatan dalam wisata alam }\end{array}$ & $\begin{array}{c}\text { G2.1, G2.2, G2.3, } \\
\text { M.1, S.1 }\end{array}$ & \\
\hline $\begin{array}{l}\text { Masyarakat terlibat dalam } \\
\text { mengembangkan daya tarik } \\
\text { wisata alam }\end{array}$ & $\begin{array}{l}\text { G2.1, G2.2, M.1, } \\
\text { M.2, M3, S.1, S.2 }\end{array}$ & \\
\hline $\begin{array}{l}\text { Sikap masyarakat terhadap } \\
\text { kegiatan dalam wisata } \\
\text { budaya }\end{array}$ & G2.1, M.1, S.1 & \\
\hline $\begin{array}{l}\text { Masyarakat terlibat dalam } \\
\text { mengembangkan daya tarik } \\
\text { wisata budaya }\end{array}$ & G2.1, M.1, S.1 & \\
\hline $\begin{array}{l}\text { Pelestarian keaslian daya } \\
\text { tarik wisata budaya }\end{array}$ & $\begin{array}{l}\text { G2.1, G2.2, M.1, } \\
\quad \text { M.2, S.1, S.2 }\end{array}$ & \\
\hline $\begin{array}{l}\text { Pengelolaan sampah secara } \\
\text { 3R oleh masyarakat }\end{array}$ & & $\begin{array}{c}\text { G1.1, G1.2, G2.1, M.1, } \\
\text { S.1 }\end{array}$ \\
\hline $\begin{array}{l}\text { Masyarakat menyediakan } \\
\text { kamar mandi umum }\end{array}$ & $\begin{array}{l}\text { G1.1, G1.2, G2.2, } \\
\text { M.1, M.2, S.1 }\end{array}$ & \\
\hline $\begin{array}{l}\text { Masyarakat memberikan } \\
\text { informasi wisata }\end{array}$ & $\begin{array}{l}\text { G1.1, G1.2, G2.1, } \\
\text { M.1, M.2, S.1 }\end{array}$ & \\
\hline $\begin{array}{l}\text { Masyarakat menyediakan } \\
\text { warung makan }\end{array}$ & $\begin{array}{l}\text { G1.1, G1.2, G2.1, } \\
\text { M.1, M.2, S.1 }\end{array}$ & \\
\hline $\begin{array}{l}\text { Masyarakat menyediakan } \\
\text { souvenir }\end{array}$ & $\begin{array}{c}\text { G2.1, M.2, S.1, } \\
\text { S.2 }\end{array}$ & G1.1, G2.3, M.1, M.3 \\
\hline ") Kode : “Ax.y” & & \\
\hline $\begin{array}{l}\text { Ax = Kode stakeholder } \\
\mathrm{y}=\text { Urutan kutipan par } \\
\text { Sumber : Penulis, } 2018\end{array}$ & dalam transkrip & \\
\hline
\end{tabular}

Tabel 6.

Content Analysis pada Aspek Ekonomi

\begin{tabular}{|c|c|c|}
\hline \multirow{2}{*}{ Sub Variabel } & \multicolumn{2}{|c|}{ Indikasi } \\
\hline & Terpenuhi & Terpenuhi \\
\hline $\begin{array}{l}\text { Lapangan kerja bagi } \\
\text { melalui daya tarik wisata } \\
\text { alam }\end{array}$ & $\begin{array}{l}\text { G1.1, G2.1, M.1, } \\
\text { S.1 }\end{array}$ & \\
\hline $\begin{array}{l}\text { Tingkat pendapatan melalui } \\
\text { daya tarik wisata alam }\end{array}$ & & G2.1, G2.2, M.1, S.1 \\
\hline $\begin{array}{l}\text { Lapangan kerja melalui } \\
\text { daya tarik wisata budaya }\end{array}$ & $\begin{array}{c}\text { G1.1, G2.1, M.1, } \\
\text { S.1 }\end{array}$ & \\
\hline $\begin{array}{l}\text { Tingkat pendapatan melalui } \\
\text { daya tarik wisata budaya }\end{array}$ & & G2.1, M.1, S.1 \\
\hline $\begin{array}{l}\text { Tingkat pendapatan } \\
\text { masayarakat dengan adanya }\end{array}$ & & G2.1, M.1, S.1 \\
\hline $\begin{array}{l}\text { kamar mandi umum } \\
\text { Tingkat pendapatan }\end{array}$ & & \\
\hline $\begin{array}{l}\text { masyarakat dengan adanya } \\
\text { warung makan }\end{array}$ & & G2.1, M.1, S.1 \\
\hline $\begin{array}{l}\text { Tingkat pendapatan } \\
\text { masyarakat dengan } \\
\text { menyediakan souvenir }\end{array}$ & & G2.1, M.1, S.1 \\
\hline ) Kode : “Ax.y” & & \\
\hline $\mathrm{Ax}=$ Kode stakeholder & & \\
\hline $\begin{array}{l}\text { y }=\text { Urutan kutipan parag } \\
\text { Sumber : Penulis, } 2018\end{array}$ & dalam transkrip & \\
\hline
\end{tabular}

Berdasarkan Tabel 5, maka dapat disimpulkan bahwa dari segi sosial dan budaya, masyarakat sudah dilibatan dalam mengembangkan daya tarik wisata alam dan budaya melalui jaring aspirasi dan pembagian tugas saat kegiatan petik laut. Selain itu, masyarakat juga sudah berpartisipasi dalam menyediakan warung makan dan kamar mandi umum. Sikap masyarakat terhadap kegiatan wisata alam mendukung meskipun pada saat-saat tertentu saja sedangkan sikap 
masyarakat terhadap kegiatan budaya yaitu dengan menunjukkan sikap saling toleransi. Masyarakat juga sudah melakukan upaya pelestarian budaya petik laut melalui pembangunan jalan, meningkatkan kondusifitas, dan membentuk kelompok nelayan sebagai ketua pelaksana. Sayangnya, masyarakat belum berpartisipasi dalam melakukan pengelolaan sampah secara 3R, memberikan informasi kepada wisatawan dan menyediakan souvenir. Meskipun sudah ada potensi souvenir seperti ikan asap namun masyarakat belum mengkomersilkan ke wisatawan.

\section{Aspek Ekonomi}

Berdasarkan Tabel 6, maka dapat disimpulkan bahwa pengembangan kawasan wisata Pantai Paseban mampu memberikan lapangan kerja terhadap masyarakat Desa Paseban. Lapangan pekerjaan yang muncul dari adanya kegiatan wisata alam dan budaya meliputi warung makan, menarik retribusi dari kamar mandi umum, tempat parkir, patani semngka, dan nelayan. Namun, masyarakat belum dapat merasakan adanya peningkatan pendapatan secara tetap dari kegiatan tersebut karena kawasan wisata Pantai Paseban ramai hanya pada hari liburan.

\section{KESIMPULAN}

Karakteristik kawasan wisata Pantai Paseban belum memenuhi prinsip keberlanjutan baik khususnya prinsip lingkungan. Hal ini ditunjukkan dengan lingkungan pantai yang belum dimanfaatkan secara optimal untuk kegiatan wisata, masih adanya ancaman penambangan pasir besi, belum ada upaya pengurangan abrasi dan penggunaan kendaraan pribadi, pelayanan air bersih yang masih menggunakan air tanah, pelayanan jaringan listrik yang belum memanfaatkan SDA, serta pemusnahan sampah dengan cara dibakar. Apabila ditinjau dari aspek sosial, masyarakat belum dilibatkan dalam melakukan pengelolaan sampah secara 3R, memberikan informasi kepada wisatawan dan menyediakan souvenir. Meskipun sudah ada potensi souvenir seperti ikan asap namun masyarakat belum mengkomersilkan ke wisatawan. Sedangkan apabila ditinjau dari aspek ekonomi, masyarakat belum merasakan adanya peningkatan pendapatan baik dari adanya kegiatan wisata alam maupun budaya, kamar mandi umum,

warung makan, dan souvenir. Hal tersebut disebabkan kunjungan wisatawan yang ramai saat peak season saja.

\section{DAFTAR PUSTAKA}

[1] M. Amanda, "Analisis Dampak Ekonomi Wisata Bahari Terhadap Pendapatam Masyarakat Lokal Studi Kasus Pantai Bandulu Kabupaten Serang Provinsi Banten," Bogor, 2009.

[2] Pemerintah Kabupaten Jember, "Perda RTRW Jember Kabupaten Jember Tahun 2015-2025," Jember, 2015.

[3] N. Hidayat and F. H. Akbar, "Perjuangan Masyarakat Paseban Menjaga Kelestarian Pesisir Ujung Barat Kabupaten Jember," Media Komun. Geogr., vol. 18, pp. 77-90, 2017.

[4] Dinas Kelautan dan Perikanan, "Data Sebaran Mangrove Tahun 2016," 2016.

[5] Pemerintah Provinsi Jawa Timur, "Rencana Zonasi Wilayah Pesisir dan Laut Kabupaten Jember Tahun 2014-2019."

[6] C. A. Gunn, Tourism Planning. New York City: Taylor and Francis, 2002.

[7] D. E. Waimbo, "Pengembangan Pariwisata Berkelanjutan: Keterlibatan Mayarakat dan Peran Pemimpin Lokal di Kampung Sawinggrai Kabupaten Raja Ampat," Universitas Kristen Satya Wacana, 2012.

[8] World Tourism Organization, "Indicators of Sustainable Development Destinations-Guidebook," Madrid, 2004.

[9] C. Estuning, "Pengembangan Kawasan Wisata Bahari di Kabupaten Jember," Surabaya, 2013. 